\title{
Claudio Presta Architecture for Mathematics: The School of Mathematics at Città Universitaria in Rome
}

One obvious aspect of the relationship between architecture and mathematics is the nature of the actual places designed by architects for the mathematical community. The School of Mathematics of the Città Universitaria was designed by Giò Ponti. Claudio Presta examines Ponti's design to see how architecture can create an appropriate space for doing mathematics. What is the meaning, if there is one? What are the motives that drove the architect to create a building expressly for the School of Mathematics and not a simple/complex building in which the School could simply be housed? Ponti provides an answer by following the shape of the Greek theater for one part of the building, while the dimensions of the other part tend towards the Golden Section.

\section{Editor's note}

One obvious aspect of the relationship between architecture and mathematics is the nature of the actual places designed by architects for the mathematical community. If you come to Rome, take the time to visit the Department of Mathematics of the Città Universitaria designed by Giò Ponti. In the 1990s restoration of the buildings was finally entrusted to specialists. For example, the atrium once again has its frosted glass, put back in order to stay faithful to the original design.

As a user, I can tell you that when you enter into the atrium you have the impression of entering into a beautiful milky light, white and shadowless. Cecilia Bernardini, the Roman restoration architect, suggests that Giò Ponti probably designed an "abstract light" for us mathematicians. It is a very beautiful image, that helps interpret some facts. For instance, in support of this notion, it is interesting to think that the front portion of the building, with its frosted glass and its milky light, was originally given over to "Pure Mathematics".

From the bare and essential atrium you go into the corridor that leads to a vast internal courtyard. Here the glass is transparent, and the light direct. Next you go to a part of the building shaped like a horseshoe, originally given over to Applied Mathematics.

As a mathematician, I thank the architect who chose to compose with light in order to create spaces in which we recognize ourselves.

Laura Tedeschini Lalli

Guest Editor, Nexus Network Journal vol. 7 no. 1 (Spring 2005)

\section{The Design of Città Universitaria}

In 1930, by express decree of the government, an area of 220,000 square meters of an growing area to the west of the city was assigned for the construction of the University of Rome. The construction would give expression to the modern rationalist and avant-garde sensitivities, within some limits:

The architecture of Città Universitaria, in its absolute simplicity, does not renounce any of the postulates of modernism, but its general concept, however, was born in a context that was classically Mediterranean. No concessions were made to the formulas of the ostentatious 
ultrarationalist (such as the great horizontal stripes of glass, or the masses planted in the empty spaces of the ground floor and raised on slender pilasters).

Stereometric cubic shapes are organized according to an open aggregation and decoration is almost totally lacking (fig. 1).

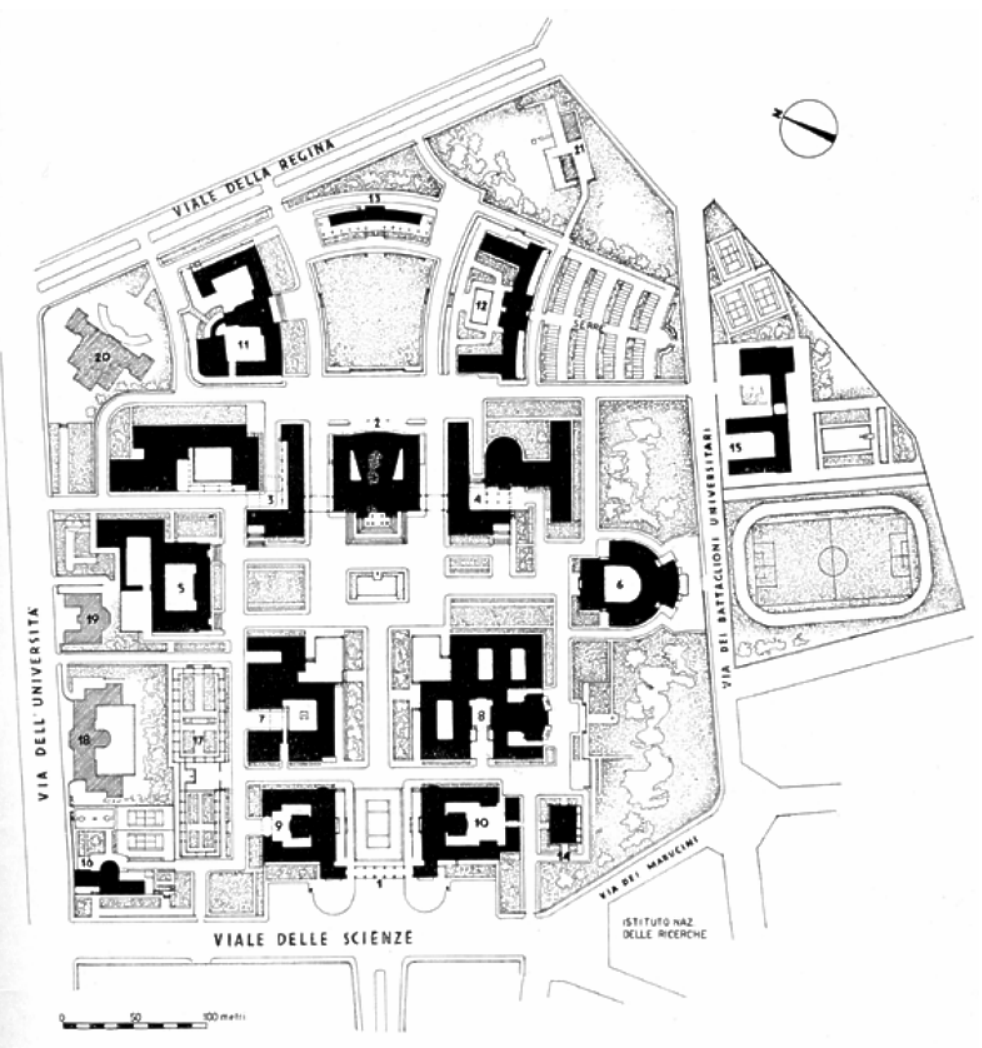

Fig. 1. The general plan of Città Universitaria

However, the general layout of the Città is arranged following the canons of historic architecture, seen from the point of view of urban design:

...I wanted, in this way, to express in a very modern way the ideas of the best urban traditions that we have derived from Greek-Roman antiquity and from our Renaissance. It is the concept of the Agora and the "Forum" of the piazzas of the 1400s and 1500s, that is, the full and complex expression of our urban building that translates into this new organism and perpetuates in modern forms the spirit of antique civilization.

Marcello Piacentini, who was responsible for the program and the plan, shared with his times the idea of government and command that is expressed in the distribution of the buildings and, keeping the institutional aspect in mind more than the cultural, situates the Rectorate at the center of the plan, with Literature and Law (Philosophy and Rhetoric) next to it, as the instruments that are closest to power. To one side are Mathematics and Biology, abstract sciences in support of government and knowledge, which would later become applied sciences in Physics and Chemistry, 
which were located immediately on the other side of the great Agora. But the plan layout could also be interpreted as an organism with a distinctly basilican aspect, where the Rectorate would occupy the place of the main altar, Literature and Law as deposits of logic in the place of the sacristy, Mathematics and Biology in the place of altars in the transepts, and then the nave with Physics and Chemistry running to the entrance, which opens to the west.

Some of the best Italian architects were chosen to realize Città Universitaria and each was assigned a precise task. In three years Foschini, Pagano, Ponti, Michelucci, Rapisardi, Capponi, Calza Bini, Fariello, Muratori, Minnucci and Montuori would bring to life the largest institution of learning in Italy, still known by the name of Sapienza, 'Wisdom' or 'Knowledge', given to the original home of the university with its architecture by Borromini and Della Porta.

\section{The School Of Mathematics}

The principle façade of the building for the School of Mathematics, designed by Giò Ponti, is directly related to the great piazza of Città Universitaria (fig. 2), and towards which the façades of the other buildings are oriented as well, just as architect Piacentini had conceived it. "The building of the School of Mathematics," Piacentini himself said, "is situated on the transversal axis of the forum." Looking at the plan layout of Città Universtaria as it appears in its first conception without the later revisions it is possible to see the substantial differences that characterize Ponti's design.

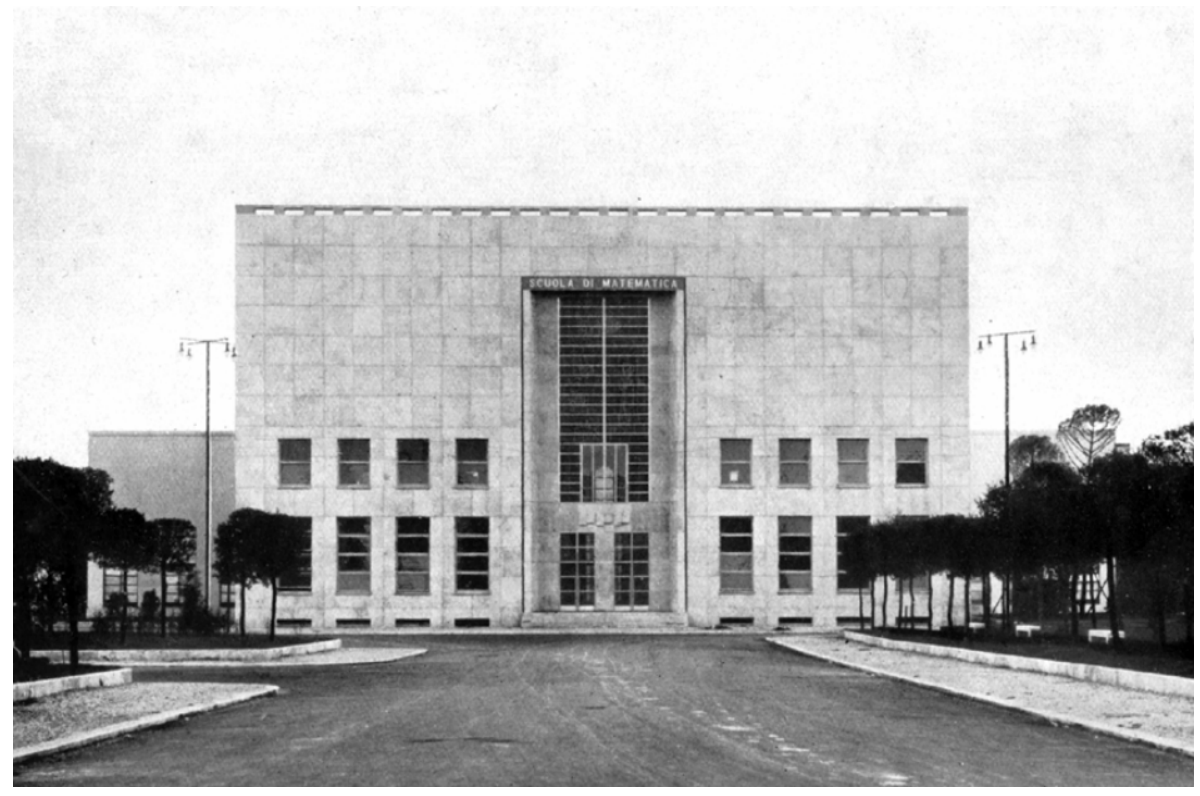

Fig. 2. The principle facade of the School of Mathematics

It is then in the design of the individual buildings, each entrusted, as we mentioned, to a different architect, that the space is reinterpreted in a modern and rational sense, a modernity that is freer in plan that in elevation, restricted by the control of symmetry and by the use of materials such as travertine and brick. All of the buildings, that is, except one: the School of Mathematics. 
Architect Ponti decided perhaps to reveal the matrix of the whole of Città Universitaria and in his building proposes, inversely, an elevation that is freer than the plan: this gives him the chance to create analogies with an architecture determined by time-honored historic characteristics. The only architect of Città Universitaria to do so, he uses triangular and circular forms for the doors and windows, where other architects accepted the restriction imposed against forcing a rational vocabulary on their designs. Thus it is that while in plan (fig. 3) Ponti uses a classical shape contrary to the other architects but in keeping with the campus design - in elevation he doesn't fail to introduce various innovations that arise from his natural way of thinking and his design practice, he who is perhaps less desirous of modernity than anyone.

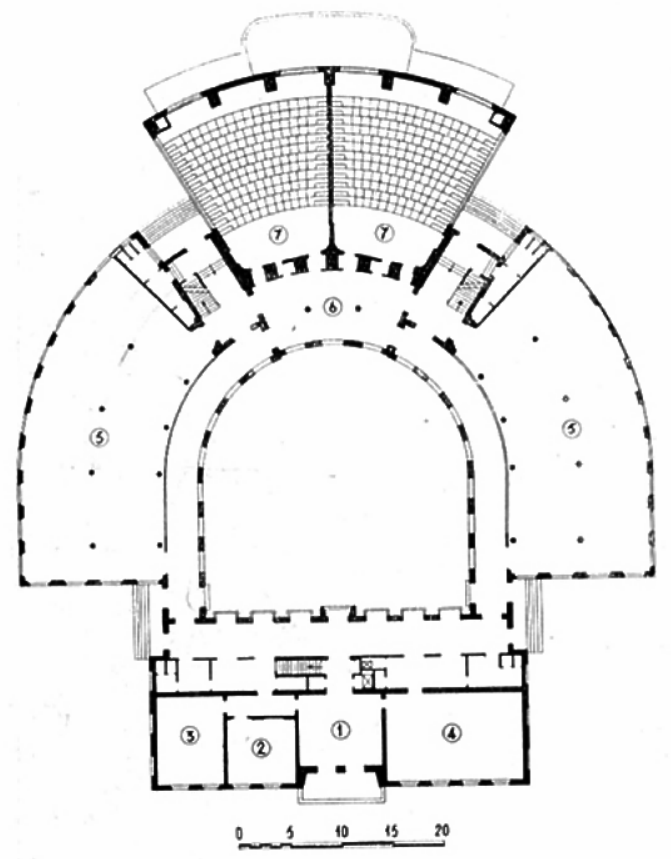

Fig. 3. The plan of the School of Mathematics

This is particularly true as regards the materials. Ponti, like the other architects, uses travertine for the exterior surfaces, but he uses the slabs in a way so as not to falsify them, thus avoiding making the walls into banalities. He wasn't want to mimic block walls and so create an architecture that is presumptuous: he is well aware that he is using thin slabs and intends to make the thickness of the veneer immediately evident. Thus in a single gesture he empties the building of a potent rhetoric possibility: the slabs are in fact set in an orthogonal grid, giving the building a look that is "cleaner" and lighter.

What is the meaning, if there is one? What are the motives that drove the architect to create a building expressly for the School of Mathematics and not a simple/complex building in which the School could simply be housed?

Ponti provides an answer in following the shape of the Greek theatre (fig. 4): this is the only shape that accords with the principles of acoustics, the only one already present in nature: in fact, 
the construction of the theatre at the appropriate scale is an artifice based on the effectiveness of natural caves for the propagation of sound, first attempted centuries ago.

The nature and propagation of sound respond to precise mathematical laws, as well as laws of optics that also involve perspective, all of which are taken advantage of by the theatre. But Ponti doesn't interpret the form of the theatre as a metaphor; he doesn't intend to use it to create an ideological content for the discipline as a cultured humanist would. The plan is composed of two architectonic elements, one with a rectangular form, the other horseshoe-shaped, with the cavea that faces the stage rather than turning in on itself, as happens in the at least in the classical form of the Greek theatre. It seems evident, in this light, that the design recalls a particular type of theatre, such as that at Eretria, which Ponti must have felt was better suited to the purpose of his building.

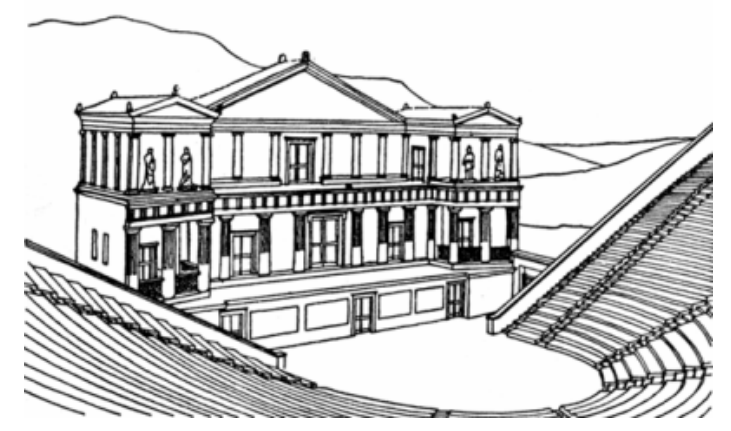

Fig. 4. The Greek theatre

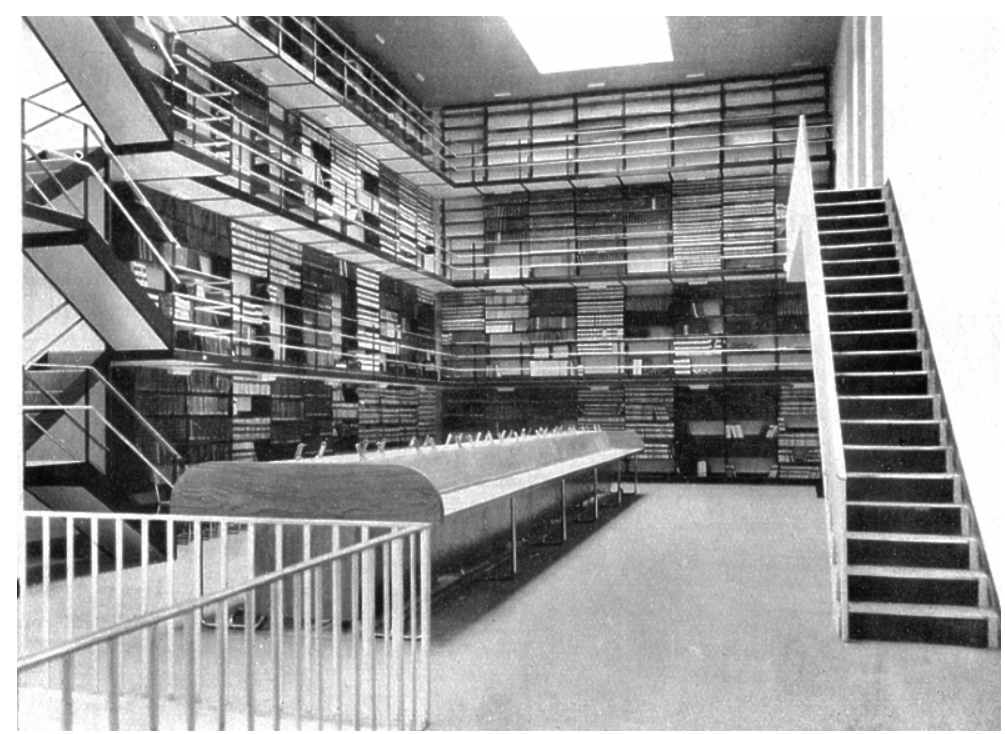

Fig. 5. The library

The second building is, as we said, horseshoe-shaped, and its complexity permits the designer to connect more autonomously as well as more incisively and meaningfully to the overall design of the campus. 
As regards the arrangement of the spaces of the School, in the first, rectangular, building are situated the administrative offices and the library (fig. 5).

In the second building are located the classrooms. The functions of all the spaces here are reflected on the building's exterior: a whole that is deconstructed and fragmented. The design studios located along the two arms are made evident (figs. 6); the stairwells automatically located in the place of the "vomitoria"; and finally the stepped lecture halls (fig. 7), called "towers" by Piacentini. The richness of all of this is in opposition to the theory that holds that the plan of a theater can only be broken down into volumes that are simple and unadorned.

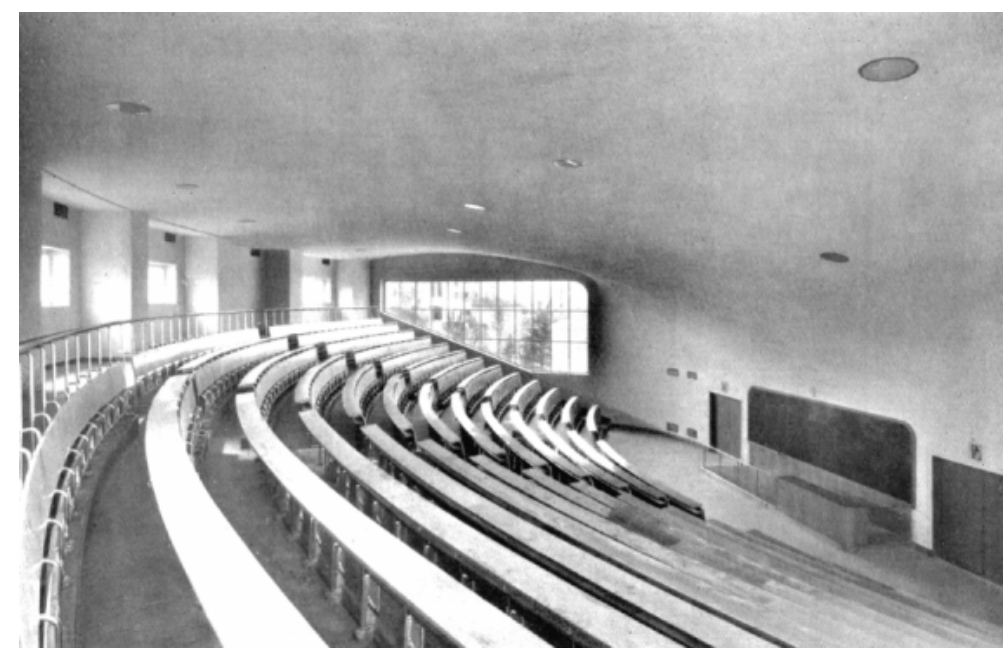

Fig. 6. A classroom in the School of Mathematics

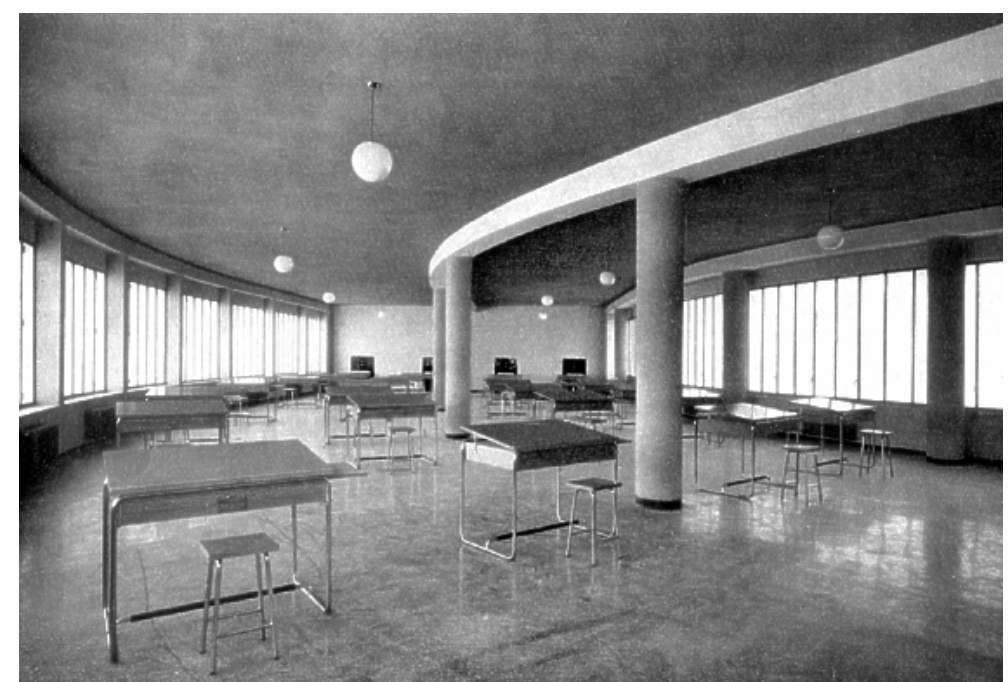

Fig. 7. A design studio in the School of Mathematics 
The bodies of the classrooms, solid and curved with but few openings in the exterior walls, becomes the immense apse of the transept of the campus. All of the elements of the theater are present: the stage, the proscenium, the orchestra and the cavea. But no plays are given here: there is rather an immersion in the deserted, metaphysical atmosphere of contemporary painting that inspired the architect.

"Thanks to number all becomes beautiful" (Pythagoras); "Measure is manifest above all in the double guise of sonorous harmony and visible symmetry" (Bodei). If the concept of beauty recalls the ideas of measure and order, together with harmony and symmetry, what can contain within itself all these qualities if not the Golden Section, which pervades the forms of nature? The body to which the main façade of the School of Mathematics pertains is the element that relates to the great piazza of Città Universitaria. Its dimensions -- width, height and depth -- tend towards the Golden Section and describe a monolith in which Ponti deposits the true meaning of his aesthetic and culture choices. And finally, how can we describe the end of the handrail of the stairs if not as a logarithmic spiral (fig. 8)?

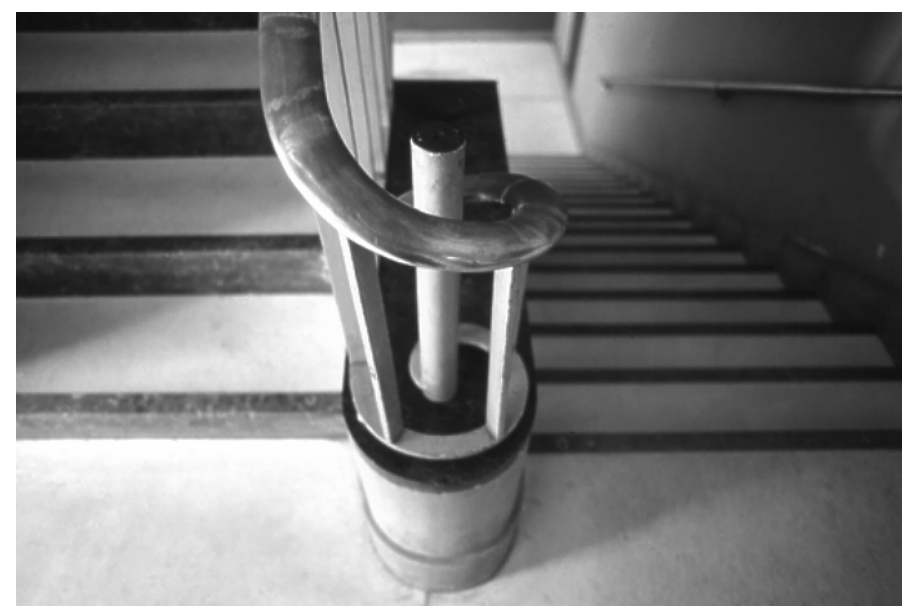

Fig. 8. A newel of the handrail in the stairs

Translated from the Italian by Kim Williams 